\title{
Spontaneous Remission of Acromegaly After Pituitary Apoplexy in a Middle-Aged Male
}

\author{
Sarah Alam, MD DM, Suraj Kubihal, MD DM, Alpesh Goyal, MD DM, Viveka P. Jyotsna, MD DM \\ Department of Endocrinology and Metabolism, All India Institute of Medical Sciences, New Delhi, India
}

Background: Pituitary apoplexy results from hemorrhage, infarction, or hemorrhagic infarction within a pituitary tumor. Subclinical or clinical apoplexy is not uncommon in acromegaly, owing to the large size of the tumor at initial detection. Growth hormone excess in acromegaly often persists following surgery. However, in rare instances, pituitary apoplexy may present a spontaneous cure to growth hormone excess.

Case Report: A 40-year-old male presented with holocranial headache for the past 16 years that had worsened in severity during the prior year. Two months before presentation, he experienced a severe headache that he described as the worst headache of his life. The patient had prominent acromegaloid features that he ignored, as they seemed to cause no harm. The patient had no signs of clinically active disease. Magnetic resonance imaging of the brain revealed a pituitary macroadenoma with evidence of hemorrhage. Serum insulin-like growth factor 1 and oral glucose-suppressed serum growth hormone levels were normal, suggestive of inactive or silent disease. Pituitary apoplexy causing spontaneous remission of acromegaly was diagnosed, and close follow-up was planned for the evolution of hypopituitarism.

Conclusion: This case highlights a rare presentation of acromegaly in which an episode of symptomatic pituitary apoplexy revealed the diagnosis of pituitary adenoma and led to the cure of growth hormone hypersecretion.

Keywords: Acromegaly, apoplexy, headache, spontaneous remission

Address correspondence to Alpesh Goyal, MD DM, Department of Endocrinology and Metabolism, All India Institute of Medical Sciences, Sri Aurobindo Marg, Ansari Nagar, Ansari Nagar East, New Delhi, India 110029. Tel: 91-011-26593237. Email: alpeshgoyal89@gmail.com

\section{INTRODUCTION}

Pituitary apoplexy is a rare but potentially fatal clinical syndrome that results from hemorrhage, infarction, or hemorrhagic infarction within a pituitary tumor. Pituitary apoplexy has been described at an incidence of 0.17 episodes per 100,000 patients per year, affecting approximately $2 \%$ to $12 \%$ of patients with pituitary adenoma. ${ }^{1}$ The clinical presentation is characterized by symptoms of acute onset severe headache in association with vomiting, visual disturbances, cranial nerve palsies, loss of consciousness, and meningismus. However, pituitary apoplexy may be subclinical or asymptomatic in up to one-fourth of patients with pituitary adenoma and is incidentally discovered on imaging or at autopsy. ${ }^{2-4}$

Precipitating factors for pituitary apoplexy include head trauma, major surgery (especially orthopedic and cardiac surgeries), uncontrolled hypertension, diabetes mellitus, anticoagulant use, cranial irradiation, dopamine agonist therapy, and dynamic testing. .-10 $^{\text {The etiopathogenesis for }}$ development of pituitary apoplexy includes the outgrowth of a pituitary tumor in relation to its blood supply and compression of the pituitary gland vascular supply by the expanding tumor mass, resulting in necrosis and infarction. ${ }^{11}$ Pituitary apoplexy is more often reported with nonfunctioning pitu- itary adenomas (NFPAs) than with functioning adenomas, an observation attributed to the fact that NFPAs are often diagnosed late when they are already quite large in size. ${ }^{11,12}$ However, the association with NFPAs may be slightly overestimated, as functionality may not be apparent because of the pituitary damage caused by apoplexy. ${ }^{13}$ Pituitary apoplexy has also been described with prolactinomas, corticotropinomas, and growth hormone-producing tumors.

The diagnosis of pituitary apoplexy is established via computed tomography or magnetic resonance imaging (MRI) of the brain demonstrating a pituitary tumor with evidence of necrosis and/or hemorrhage. Historically, pituitary apoplexy was considered a neurosurgical emergency, and surgical decompression was performed in all cases. ${ }^{3}$ However, studies have demonstrated favorable outcomes with conservative management, suggesting that surgical treatment should be reserved for select patients with visual defects and a reduced level of consciousness. ${ }^{14-17}$

Pituitary apoplexy can result in multiple acute endocrine insufficiencies, the most common and clinically significant being secondary adrenal insufficiency. ${ }^{18,19}$ When it is a complication of functional pituitary adenoma, pituitary apoplexy can sometimes (rarely) lead to the resolution of hormonal hypersecretion and remission of the disease state. ${ }^{20-22}$ We 


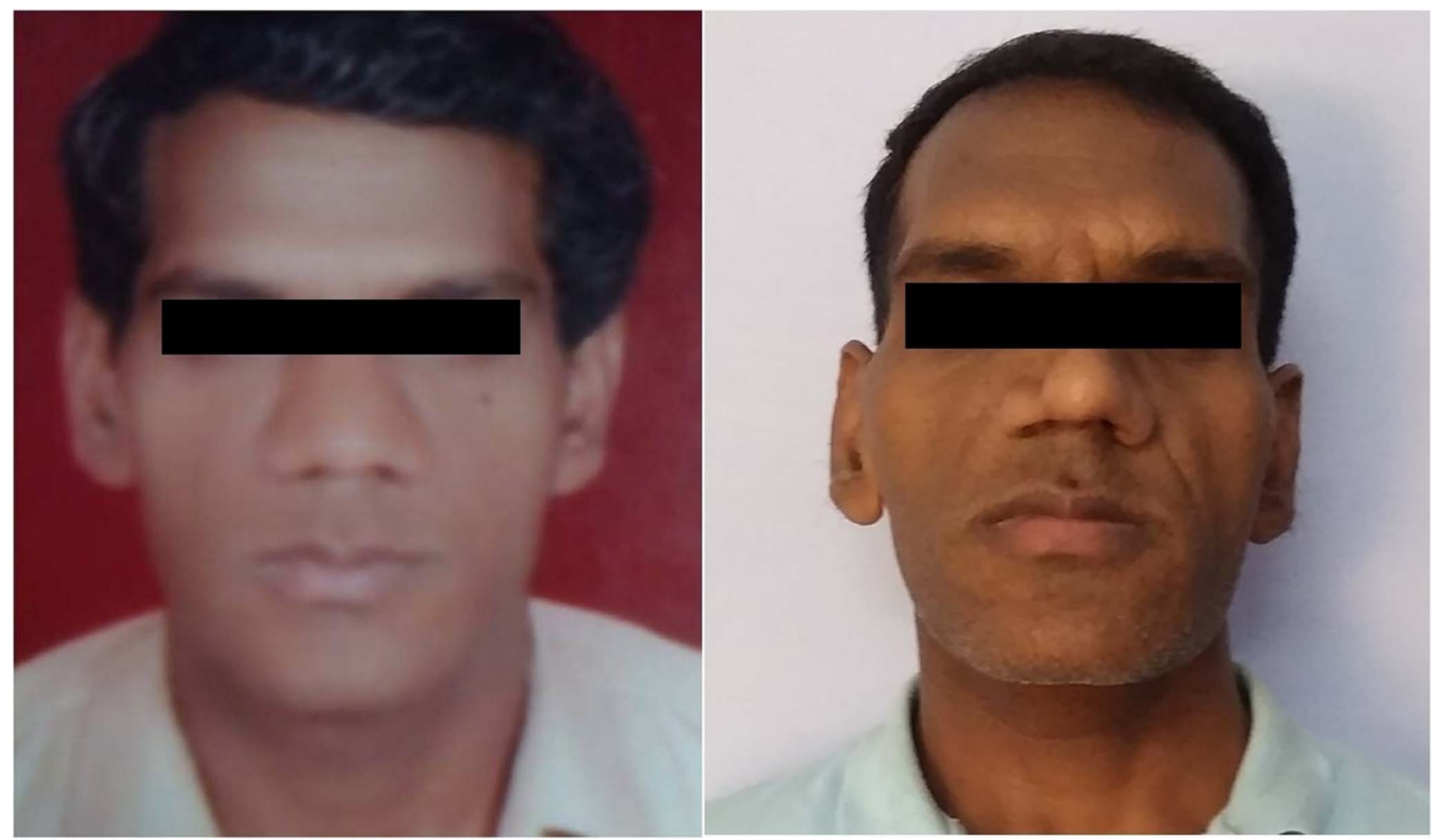

Figure 1. Clinical photographs show facial features of acromegaly in the patient in 2008 (left panel) and in 2019 (right panel).

describe such an occurrence in a middle-aged male with acromegaly who had spontaneous cure of his growth hormone excess state following an episode of symptomatic pituitary apoplexy.

\section{CASE REPORT}

A 40-year-old male presented to our clinic with a history of holocranial headaches for the past 16 years that had gradually worsened. For the 1 year prior to presentation, he was troubled on an almost daily basis with severe headaches that also caused frequent nocturnal awakenings. He had been treated elsewhere for migraine headaches without significant symptomatic improvement.

He had noticed acromegaloid changes in the form of coarsening facial features and an increase in the size of his hands and feet during the prior 10 years. However, he did not seek medical attention for these changes, as they seemed to cause no harm. The patient had no history of seizures, loss of consciousness, recurrent vomiting, or episodes of transient visual obscurations. He denied a history of hypertension or diabetes mellitus. Two months before the current presentation, he had an episode of severe headache that he described as the worst headache of his life. The episode lasted for 4 to 5 hours, and he was treated with intravenous analgesics and fluids. No nausea, vomiting, dizziness, blurring of vision, diplopia, or any other focal neurologic deficit was associated with the episode. He denied a history of head trauma, anticoagulant use, prior surgical intervention, cranial irradiation, and pituitary dynamic testing.

On examination, the patient's pulse rate was $84 / \mathrm{min}$, and blood pressure was $128 / 76 \mathrm{mmHg}$. His height, weight, and body mass index were $175 \mathrm{~cm}, 74 \mathrm{~kg}$, and $24.1 \mathrm{~kg} / \mathrm{m}^{2}$, respectively. The clinical features of acromegaly were confirmed on physical examination; however, no signs of active disease were noted (Figures 1, 2, and 3). Visual acuity was $6 / 6$ assessed using a Snellen chart, and field testing done by confrontation perimetry was normal. The remainder of the patient's general and systemic examination was unremarkable.

Laboratory evaluation (Table) revealed normal complete blood count, liver, and renal function tests. Endocrine profile included normal serum free thyroxine, thyroid-stimulating hormone, 8 am cortisol, testosterone, prolactin, and insulinlike growth factor 1. Growth hormone suppression test with $75 \mathrm{~g}$ glucose revealed nadir growth hormone of $<1 \mu \mathrm{g} / \mathrm{L}$ (normal). These investigations suggested normal pituitary function with no evidence of growth hormone hypersecretion. MRI showed enlarged pituitary fossa, a 12-mm macroadenoma in the right half of the pituitary gland, and evidence of hemorrhage within the mass (Figure 4).

The differentials of acute severe headache include subarachnoid hemorrhage, pituitary apoplexy, hypertensive encephalopathy, acute cerebral ischemia, intracranial hypotension (spontaneous or post lumbar puncture), idiopathic intracranial hypertension, posttraumatic headache, substance use or withdrawal-related headache, migraine, cluster headache, and idiopathic thunderclap headache. Our patient had severe acute headache with clinical features suggestive of acromegaly and neuroimaging evidence of pituitary macroadenoma with hemorrhage, suggestive of pituitary apoplexy. However, clinical and biochemical markers of acromegaly activity were normal, suggestive of inactive disease. The patient had no history of 


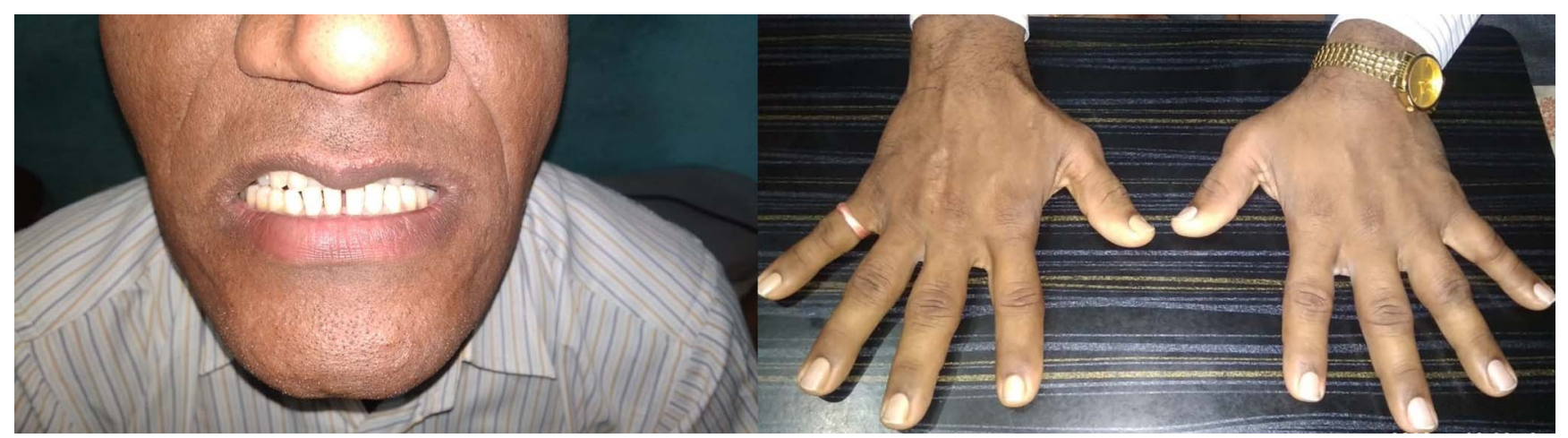

Figure 2. Clinical photographs at admission show dental malocclusion and increased interdental spaces (left panel) and enlarged hands (right panel).

transsphenoidal surgery or cranial irradiation. Pituitary apoplexy causing spontaneous remission of acromegaly was therefore diagnosed.

Because the laboratory evaluation did not reveal any endocrine abnormalities, no specific treatment was initiated. The severity of headache reduced significantly during the course of the patient's hospital stay, and he was advised to take oral analgesic paracetamol when needed. He was counseled regarding the need for close follow-up to detect hypopituitarism and was discharged with a plan to repeat pituitary function and neuroimaging at an interval of 3 to 6 months.

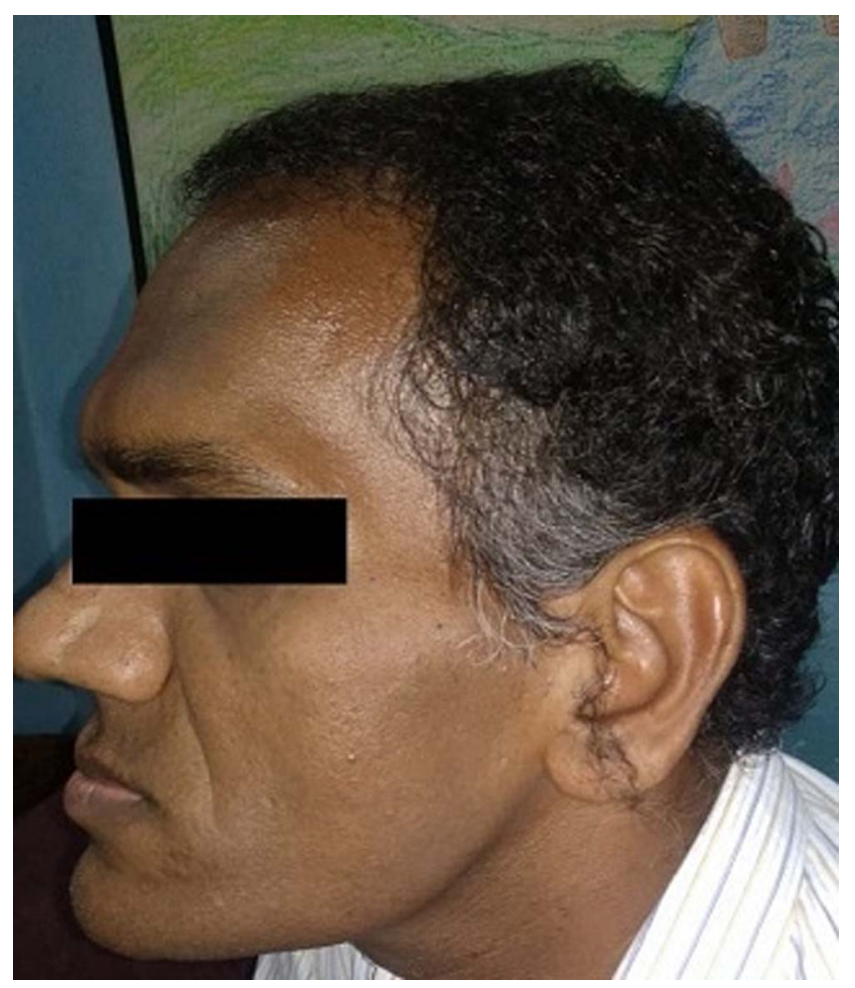

Figure 3. Clinical photograph at admission shows prognathism.

\section{DISCUSSION}

The diagnosis of acromegaly is often delayed by many years (average 10 to 12 years) because of the slow and subtle progression of physical findings that patients fail to notice. ${ }^{23}$ In fact, many patients are diagnosed on the appearance of symptomatic mass effects caused by the tumor or incidentally when seeing a physician for some other ailment. The delay in diagnosis exposes patients to the risk of tumor progression and a state of uncontrolled growth hormone hypersecretion, resulting in increased morbidity and mortality. Our patient had had symptoms of growth hormone excess for 10 years, but he ignored them because the symptoms did not result in any functional limitation. However, the symptom of headache prompted him to see multiple physicians who failed to diagnose the primary disease.

In more than $95 \%$ of cases of acromegaly, the cause for growth hormone hypersecretion is a somatotroph pituitary adenoma, commonly macroadenoma. ${ }^{24}$ Surgery is the first line of therapy for most patients with acromegaly. However, remission rates are only $80 \%$ for patients with microadenoma and $<50 \%$ for those with macroadenoma, ${ }^{25}$ implying that a large proportion of patients are left with a persistent growth hormone hypersecretion state, requiring consideration for medical therapy (eg, somatostatin analog, pegvisomant, cabergoline), radiation therapy (stereotactic radiosurgery, fractionated radiotherapy), or repeat surgery. Our patient had an undiagnosed pituitary macroadenoma that bled, possibly because of its large size, and resulted in the spontaneous cure of acromegaly without therapeutic intervention.

Clinical remission of acromegaly following apoplexy is extremely rare and to our knowledge has only been reported in 29 cases in the literature. ${ }^{26-30}$ While a precipitating event such as gastrointestinal hemorrhage or gadolinium-DTPA (diethylenetriaminepentaacetic acid) administration causing an acute change in blood pressure was identified by some authors, no trigger could be identified by others. ${ }^{26,29,30}$ Our patient had no recognizable precipitating factor for the acute event.

Pituitary apoplexy is an important cause of hypopituitarism. A literature review reveals that more than twothirds of patients who had cure of acromegaly following pituitary apoplexy developed other pituitary hormone 
Table. Laboratory Results at Presentation

\begin{tabular}{|c|c|c|}
\hline Parameter & Result & Reference Range \\
\hline Hemoglobin, g/L & 141 & $120-150$ \\
\hline Total leukocyte count, cells/L & $6.75 \times 10^{9}$ & $4-11 \times 10^{9}$ \\
\hline Platelets, cells/L & $209 \times 10^{9}$ & $250-450 \times 10^{9}$ \\
\hline Urea, $\mathrm{mmol} / \mathrm{L}$ & 2.8 & $3.33-6.66$ \\
\hline Creatinine, $\mathrm{mmol} / \mathrm{L}$ & 0.08 & $0.03-0.11$ \\
\hline Uric acid, mmol/L & 0.32 & $0.15-0.39$ \\
\hline Calcium, mmol/L & 2.27 & $2.12-2.59$ \\
\hline Phosphate, $\mathrm{mmol} / \mathrm{L}$ & 1.55 & $1.39-1.74$ \\
\hline Serum alkaline phosphatase, IU/L & 295 & $240-840$ \\
\hline $\begin{array}{l}\text { Serum glutamic oxaloacetic transaminase/Serum } \\
\text { glutamic pyruvic transaminase, IU/L }\end{array}$ & $19 / 24$ & $<40 /<40$ \\
\hline Albumin, g/L & 45 & $35-45$ \\
\hline Sodium/Potassium, mmol/L & $145 / 4.7$ & $135-145 / 3.5-5.5$ \\
\hline Total cholesterol, $\mathrm{mmol} / \mathrm{L}$ & 4.18 & $<5.17$ \\
\hline Triglycerides, mmol/L & 1.8 & $<1.70$ \\
\hline Low density lipoprotein cholesterol, $\mathrm{mmol} / \mathrm{L}$ & 2.58 & $<3.36$ \\
\hline High density lipoprotein cholesterol, mmol/L & 0.77 & $>1.03$ \\
\hline Total thyroxine, $\mathrm{nmol} / \mathrm{L}$ & 141.5 & $65.6-181.5$ \\
\hline Free thyroxine, pmol/L & 18.53 & $11.97-21.88$ \\
\hline Thyroid-stimulating hormone, mIU/L & 1.27 & $0.27-4.2$ \\
\hline Testosterone, $\mathrm{nmol} / \mathrm{L}$ & 11.19 & $8.3-28.77$ \\
\hline 8 am cortisol, $\mathrm{nmol} / \mathrm{L}$ & 293.2 & $171.0-535.1$ \\
\hline Prolactin, $\mu \mathrm{g} / \mathrm{L}$ & 4.7 & $4.6-21.4$ \\
\hline Insulin-like growth factor $1, \mu \mathrm{g} / \mathrm{L}$ & 173.9 & $88.3-209.9$ \\
\hline \multicolumn{3}{|l|}{ Growth hormone suppression test, $\mu \mathrm{g} / \mathrm{L}$} \\
\hline $0 \mathrm{~min}$ & 0.476 & $\begin{array}{l}\text { Nadir }<1 \mu \mathrm{g} / \mathrm{L} \\
\quad \text { considered normal. }\end{array}$ \\
\hline $30 \mathrm{~min}$ & 0.169 & \\
\hline $60 \mathrm{~min}$ & 0.080 & $\begin{array}{l}\text { Nadir }>1 \mu \mathrm{g} / \mathrm{L} \text { suggests } \\
\text { growth hormone } \\
\text { excess. }\end{array}$ \\
\hline $90 \mathrm{~min}$ & 0.143 & \\
\hline $120 \mathrm{~min}$ & 0.064 & \\
\hline
\end{tabular}
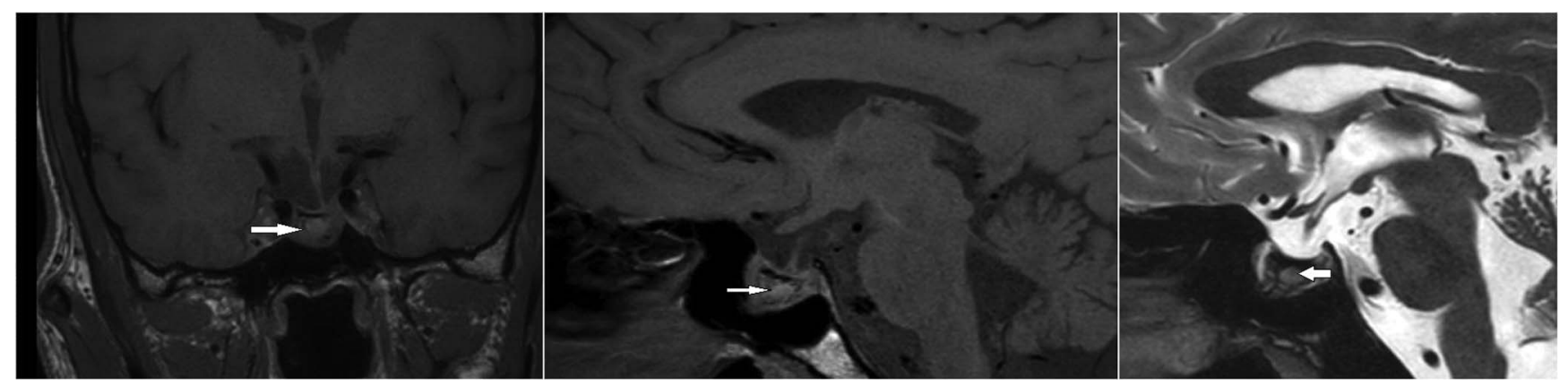

Figure 4. Magnetic resonance imaging of sellar region. T1-weighted coronal (left panel) and sagittal (middle panel) and T2weighted sagittal (right panel) images show macroadenoma (arrows) with stalk deviation toward the left side. The lesion is hyperintense on T1-weighted images and hypointense on the T2-weighted image, suggestive of hemorrhage within. 
deficiencies, and a small fraction $(<10 \%)$ even evolved to panhypopituitarism. ${ }^{26}$ This observation highlights the importance of close surveillance for pituitary function in any patient with suspected or confirmed pituitary apoplexy. While we found no pituitary hormone deficits in our patient at the current presentation, he will be closely followed for potential deficits.

\section{CONCLUSION}

Pituitary apoplexy should be considered in the differential diagnosis of a patient presenting with acute severe headache. In rare instances, pituitary apoplexy may result in a spontaneous cure of the pituitary hypersecretion state. Patients with suspected or confirmed pituitary apoplexy should undergo periodic assessment for the development of hypopituitarism. This case highlights a rare presentation of acromegaly in which an episode of symptomatic pituitary apoplexy revealed the diagnosis of pituitary adenoma and led to the cure of growth hormone hypersecretion.

\section{ACKNOWLEDGMENTS}

The authors thank Dr Devasenathipathy Kandasamy (Department of Radiodiagnosis) and Dr Yashdeep Gupta (Department of Endocrinology and Metabolism) for their help in managing the patient. The authors have no financial or proprietary interest in the subject matter of this article.

\section{REFERENCES}

1. Raappana A, Koivukangas J, Ebeling T, Pirilä T. Incidence of pituitary adenomas in Northern Finland in 1992-2007. J Clin Endocrinol Metab. 2010;95:4268-4275.

doi: 10.1210/jc.2010-0537

2. Kinoshita Y, Tominaga A, Usui S, Arita K, Sugiyama K, Kurisu K. Impact of subclinical haemorrhage on the pituitary gland in patients with pituitary adenomas. Clin Endocrinol (Oxf). 2014;80(5):720-725. doi: 10.1111/cen.12349

3. Bonicki W, Kasperlik-Zaluska A, Koszewski W, Zgliczyński W, Wisławski J. Pituitary apoplexy: endocrine, surgical and oncological emergency. Incidence, clinical course and treatment with reference to 799 cases of pituitary adenomas. Acta Neurochir (Wien). 1993;120(3-4):118-122.

doi: 10.1007/BF02112028

4. Onesti ST, Wisniewski T, Post KD. Clinical versus subclinical pituitary apoplexy: presentation, surgical management, and outcome in 21 patients. Neurosurgery.1990;26(6):980-986.

5. Dev R, Singh SK, Sharma MC, Khetan P, Chugh A. Post traumatic pituitary apoplexy with contiguous intra cerebral hematoma operated through endonasal route-a case report. Pituitary. 2007;10:291-294. doi: 10.1007/s11102-007-0015-0

6. Tansel T, Ugurlucan M, Onursal E. Pituitary apoplexy following coronary artery bypass grafting: report of a case. Acta Chir Belg. 2010;110: 484-486. doi: 10.1080/00015458.2010.11680661

7. Goel V, Debnath UK, Singh J, Brydon HL. Pituitary apoplexy after joint arthroplasty. J Arthroplasty. 2009;24:826.e827-810. doi: 10.1016/j.arth.2008.06.021

8. Matsuura I, Saeki N, Kubota M, Murai H, Yamaura A. Infarction followed by hemorrhage in pituitary adenoma due to endocrine stimulation test. Endocr J. 2001;48:493-498. doi: $10.1507 /$ endocrj. 48.493

9. Chng E, Dalan R. Pituitary apoplexy associated with cabergoline therapy. J Clin Neurosci. 2013;20:1637-1643. doi: 10.1016/j.jocn.2013.02.027
10. Biousse V, Newman NJ, Oyesiku NM. Precipitating factors in pituitary apoplexy. J Neurol Neurosurg Psychiatry. 2001;71:542-545. doi: 10.1136/jnnp.71.4.542

11. Briet C, Salenave S, Bonneville J, Laws ER, Chanson P. Pituitary apoplexy. Endocr Rev. 2015;36(6):622-645. doi: 10.1210/er.2015-1042

12. Arita K, Tominaga A, Sugiyama K, et al. Natural course of incidentally found nonfunctioning pituitary adenoma, with special reference to pituitary apoplexy during follow-up examination. J Neurosurg. 2006;104:884-891. doi: $10.3171 /$ jns.2006.104.6.884

13. Capatina C, Inder W, Karavitaki N, et al. Management of endocrine disease: pituitary tumour apoplexy. Eur J Endocrinol. 2015;172(5): R179-R190. doi: 10.1530/EJE-14-0794

14. Maccagnan $P$, Macedo CL, Kayath MJ, Nogueira RG, Abucham J. Conservative management of pituitary apoplexy: a prospective study. J Clin Endocrinol Metab. 1995;80(7):2190-2197. doi: 10.1210/jcem.80.7.7608278

15. Ayuk J, McGregor EJ, Mitchell RD, Gittoes NJ. Acute management of pituitary apoplexy-surgery or conservative management? Clin Endocrinol (Oxf). 2004;61 (6):747-752. doi: 10.1111/j.1365-2265.2004.02162.x

16. Gruber A, Clayton J, Kumar S, Robertson I, Howlett TA, Mansell P. Pituitary apoplexy: retrospective review of 30 patients-is surgical intervention always necessary? Br J Neurosurg. 2006;20(6):379-385. doi: 10.1080/02688690601046678

17. Leyer C, Castinetti F, Morange I, et al. A conservative management is preferable in milder forms of pituitary tumor apoplexy. J Endocrinol Invest. 2011;34(7):502-509.

18. Randeva HS, Schoebel J, Byrne J, Esiri M, Adams CB, Wass JA. Classical pituitary apoplexy: clinical features, management and outcome. Clin Endocrinol (Oxf). 1999;51(2):181-188. doi: 10.1046/j.1365-2265.1999.00754.x

19. Rajasekaran $S$, Vanderpump $M$, Baldeweg $S$, et al. UK guidelines for the management of pituitary apoplexy. Clin Endocrinol (Oxf). 2011;74(1):9-20. doi: 10.1111/j.1365-2265.2010.03913.x

20. Pelkonen R, Kuusisto A, Salmi J, et al. Pituitary function after pituitary apoplexy. Am J Med. 1978;65(5):773-778. doi: 10.1016/0002-9343(78)90795-7

21. Araya V, Solís I, Lemp M, Oviedo S. Partial remission of hypercortisolism in Cushing disease after pituitary apoplexy. A case report. Rev Med Chil. 1998;126(12):1497-1501.

22. Watt A, Pobereskin L, Vaidya B. Pituitary apoplexy within a macroprolactinoma. Nat Clin Pract Endocrinol Metab. 2008;4(11):635-641. doi: 10.1038/ncpendmet0968

23. Zahr R, Fleseriu M. Updates in diagnosis and treatment of acromegaly. Eur Endocrinol. 2018;14(2):57-61. doi: 10.17925/EE.2018.14.2.57

24. Dutta P, Hajela A, Pathak A, et al. Clinical profile and outcome of patients with acromegaly according to the 2014 consensus guidelines: impact of a multi-disciplinary team. Neurol India. 2015;63:360-368. doi: 10.4103/0028-3886.158210

25. Minniti G, Jaffrain-Rea ML, Esposito V, Santoro A, Tamburrano G, Cantore G. Evolving criteria for postoperative biochemical remission of acromegaly: can we achieve a definitive cure? An audit of surgical results on a large series and a review of the literature. Endocr Relat Cancer. 2003;10(4):611-619. doi: 10.1677/erc.0.0100611

26. Fraser LA, Lee D, Cooper P, Van Uum S. Remission of acromegaly after pituitary apoplexy: case report and review of literature. Endocr Pract. 2009;15(7):725-731. doi: 10.4158/EP09126.CRR

27. Wang XL, Dou JT, Lu ZH, et al. Spontaneous remission of acromegaly or gigantism due to subclinical apoplexy of 
pituitary growth hormone adenoma. Chin Med J (Engl). 2011;124(22):3820-3823.

28. Cinar N, Metin Y, Dagdelen S, Ziyal MI, Soylemezoglu F, Erbas T. Spontaneous remission of acromegaly after infarctive apoplexy with a possible relation to MRI and diabetes mellitus. Neuro Endocrinol Lett. 2013;34(5):339-342.

29. Imaki T, Yamada S, Harada S, Tsuchiya M, Sano T, Demura H. Amelioration of acromegaly after pituitary infarction due to gastrointestinal hemorrhage from gastric ulcer. Endocr $\mathrm{J}$. 1999;46(1):147-151. doi: 10.1507/endocrj.46.147

30. Wichers M, Kristof RA, Springer W, Schramm J, Klingmüller D. Pituitary apoplexy with spontaneous cure of acromegaly and its possible relation to Gd-DTPA-administration. ActaNeurochir (Wien). 1997;139(10):992-994. doi: 10.1007/bf01411312

This article meets the Accreditation Council for Graduate Medical Education and the American Board of Medical Specialties Maintenance of Certification competencies for Patient Care and Medical Knowledge.

(C2021 by the author(s); licensee Ochsner Journal, Ochsner Clinic Foundation, New Orleans, LA. This article is an open (c) (i) access article distributed under the terms and conditions of the Creative Commons Attribution (CC BY) license (creativecommons.org/licenses/by/4.0/legalcode) that permits unrestricted use, distribution, and reproduction in any medium, provided the original author(s) and source are credited. 